16 September: A secretary phones from region to attempt to explain that form S50 must be fully completed; a new form is to be sent.

22 September: Form $S 50$ returned completed with "not applicable," "as approved by JCHMT," and "see covering letter." Covering letter enclosed to the secretary of the regional senior registrar subcommittee outlining the proposed rotation for the third time.

30 September: Acknowledgment received from region but not from the secretary of the subcommittee to whom the form S50 and letter were sent; I can only presume he is too busy or too important to attend to his own work.

18 November: Letter received from the assistant secretary to the JCHMT requesting completion of form DAPE: most of the information requested is already in their files relating to the recent inspection and approval of the posts through which she would rotate, and the remaining details were supplied by the regional dean on 4 July.

So the saga continues. Educational approval can hardly be denied but there is no way of knowing whether the Central Manpower Committee (who meet very infrequently) will give their blessing; the charade must be played out before the finale is unveiled; hopes are raised, hours of valuable time are wasted, and redundant hands are employed-if not their heads. It is hardly worth mentioning that there is still no money but that will at least be a clear-cut issue if and when the time comes. Would she do better if she now pursued her application through the Ombudsman or the Equal Opportunities Commission?

Two years ago at a conference organised by the DHSS on "Women in Medicine" Dr Rosemary Rue insisted that "a woman free and ready to train should be treated as a medical emergency." The simile was perhaps unfortunate because medical emergencies command low priority at the DHSS, but surely even the DHSS can understand that a woman's determination to continue specialist training needs to be capitalised quickly or may be lost for ever?

\section{Possible solutions}

At that same conference Dr Pamela Ashurst pointed out that lack of co-ordination, inability to obtain informed advice, and incapability to take rapid decisions were fundamental barriers to progress. She made four simple proposals: (1) an officer of the DHSS should be allotted special responsibility for approving such posts; (2) a proportion of the cost of funding these posts should come from central provision; (3) all employing authorities should nominate one person with special interest and responsibility for such posts; and (4) all colleges and faculties should nominate one officer with a special responsibility for approving such posts. Were her proposals too simple for the complicated minds of her listeners?

The nation is paying top salaries at the DHSS, in the councils for postgraduate medical education, and in the regional postgraduate organisations for experts to fashion an appropriate framework of postgraduate medical education, a framework intimately bound up with employment opportunities-whole time and part time, consultant, or subconsultant. Everyone knows that the present system for part-time specialist training is only workable because applicants give up before they are turned down, but who among those experts is capable of setting out a realistic solution? Can it be that postgraduate education is too rough a pasture for putting famous race horses out to grass or to serve as a battlefield for administrative doctors who may perhaps have strayed into the high command more by accident than by design ? Yet until the problems are clearly and courageously defined with all their consequential ramifications (provision of suitable permanent posts in particular) they never will be solved. How easy to say there is no money and to feel relieved of all responsibility to tackle the enormously complex task of planning ahead.

Our daughters deserve their training won in open competition; they also can reasonably demand the opportunity to use it. Those women who both raise families and manage to continue full-time training deserve our respect and admiration, but most women need to be helped through a period of parttime training. They need to know from the outset that a wellworn and easily found path exists; they also need the assurance of appropriate permanent employment at the end of the road. At $£ 30000$ to train a doctor and with the proportion of women medical graduates soon rising $40^{\circ}$ o, the nation would be well advised to ensure now that the DHSS is not allowed through lack of imagination, foresight, or competence to incur losses at which even the Crown Agents would turn pale.

(Accepted 14 December 1977)
Why do two intelligent patients persistently use lip salve even though there is no medical need for its use?

Minor degrees of this phenomenon are seen in men and women as well as in their pubertal sisters, who use it as a substitute for lipstick. The afflicted individuals are quite normal (though there is no reason why the occasional obsessive should not develop the habit, as does the occasional homosexual). I do not know the cause, but I suspect it to be a pleasurable relic of primitive grooming behaviour. The best treatment is to send the patients skiing, where everybody else is doing it.

$A$ retired medical laboratory technician, now aged 68, has developed multiple sessile papilloma of the urinary bladder. For many years he handled benzidine and probably other carcinogens. Is the disease notifiable as an industrial disease and might he be entitled to compensation from his employers?

Primary neoplasm of the epithelial lining of the urinary bladder is not a notifiable disease, but it is scheduled as a prescribed industrial disease. It may therefore attract industrial benefit if the conditions laid down under heading 39 in the prescribed industrial disease regulations are met. An occupation that uses or handles benzidine is one of the conditions. The question of compensation is quite different. Compensation is paid, if at all, by employers and not by the Government. Payments are made, as a rule, in the light of litigation in which negligence has been proved or is likely to be provable. The technician should therefore seek the advice of a lawyer. If he belonged to a trade union while working he could reasonably expect the union to advise or help or both in preparing a claim. Whether or not a claim would succeed would depend on the facts-for instance, whether exposure to benzidine or other relevant carcinogen could be proved, whether negligence could be proved, whether staff were warned of the dangers, and whether precautions were taken, etc. Some employers, if appraised of the facts, might be willing to make an ex gratia payment, thereby saving the time, trouble, and expense of taking the problem through the courts. It should perhaps be added that bladder tumours are not uncommon and their incidence increases with age in people with no known exposure to any of the substances mentioned in the prescribed industrial disease regulations, particularly if they have been heavy cigarette smokers. It might therefore be difficult to establish that work as a medical laboratory technician was, on balance of probabilities, the cause of bladder tumours arising after retirement.

\section{Corrections}

\section{Operation in Japan}

In this article (24-31 December 1977, p 1646) the address and name of the author at the bottom of the page should have appeared as I-4923-9 Teraodai, Tama-ku, Kawasaki-shi, Kanagawa-ken, Japan. T W M Lilley, English lecturer at Rikkyo University, Japan.

\section{Small-bowel ischaemia and the contraceptive pill}

In the leading article ( 7 January, $p$ 4) the dosage of oestrogen in the second paragraph should have read $0.05 \mathrm{mg}$ daily, not $0.5 \mathrm{mg}$. 